REVISTA DE GESTÃO ESECRETARIADO

MANAGEMENT AND ADMINISTRATIVE

PROFESSIONAL REVIEW

ISSN: 2178-9010
Revista GeSec

São Paulo, SP, Brasil

v. 12 , n. 2, p. 253-272

maio /ago. 2021

DOI: http://dx.doi.org/10.7769/gesec.v12i2.1170

\title{
Subsídios à ação criativa e intencional em instituições financeiras brasileiras
}

\section{Subsidies for creative and purposeful action in brazilian financial} institutions

Thaís Teles Firmino ${ }^{1}$

César Ricardo Maia de Vasconcelos ${ }^{2}$

\section{Resumo}

O objetivo deste artigo foi analisar as práticas de gestão de pessoas (GP) associadas às ações criativa e intencional. Para esta investigação, utilizaram-se os relatórios administrativos e as notas explicativas do Itaú Unibanco S.A., Banco Bradesco S.A. e Banco do Brasil S.A, instituições financeiras com ações na bolsa de valores brasileira (B3) possuidoras dos maiores índices de felicidade no trabalho. Como resultados, destaca-se o compromisso das organizações com as adaptações necessárias ao contexto competitivo atual marcado pelos avanços tecnológicos, o que configurou uma remodelagem das práticas de GP visando o desenvolvimento das potencialidades humanas. Percebeu-se também que estas iniciativas dão suporte às ações criativas e intencionais das pessoas. Este trabalho contribui principalmente por pesquisar os vínculos entre as práticas de gestão de pessoas e os facilitadores de ações criativas e intencionais, evidenciando como um subsidia o desenvolvimento do outro.

Palavras-chave: Recursos humanos. Gestão de pessoas. Criatividade. Felicidade no trabalho. Instituições financeiras.

\section{Abstract}

The purpose of this article was to analyze people management (PM) practices associated with creative and purposeful actions. For this investigation, we used the administrative reports and

\footnotetext{
${ }^{1}$ Doutoranda no Programa de Pós-graduação em Administração na Universidade Potiguar (UnP), Docente na Universidade Federal da Paraíba (UFPB).

${ }^{2}$ Doutor em Administração, Docente no Programa de Pós-Graduação em Administração na Universidade Potiguar $(\mathrm{UnP})$.
} 
explanatory notes from Itaú Unibanco S.A., Banco Bradesco S.A. and Banco do Brasil S.A, financial institutions with shares in the Brazilian stock exchange (B3) that had the highest levels of happiness at work. As a result, we highlight the commitment of organizations with the necessary adaptations to the current competitive context marked by technological advances, which configured a remodeling of PM practices aiming at the development of human potentialities. It was also realized that these initiatives support people's creative and purposeful actions. This work contributes mainly by researching the links between people management practices and the facilitators of creative and purposeful actions, highlighting how one subsidizes the development of the other.

Keywords: Human resources. People management. Creativity. Happiness at work. Financial institutions.

\section{Introdução}

Os meios de comunicação parecem estar continuamente informando sobre uma complexidade cada vez mais presente na atualidade com implicações ainda desconhecidas, o que pede uma nova forma de enxergar os fatos e agir no cotidiano. Questões como o convívio dos robôs com humanos, os avanços (por vezes ameaçadores) da inteligência artificial, o destaque econômico e tecnológico da China, os conflitos políticos que geram polarizações, os desafios socioambientais, as fake news, entre outros, modificam as estruturas e perspectivas de maneira cada vez mais rápida. Enquanto cidadãos comuns, muitos buscam se adaptar e se antecipar a tais mudanças, não sendo diferente com as organizações.

Essas últimas, por sua vez, sofrem pressões constantes para a inovação e adaptação (Lynn \& Akgün, 1998), uma vez que as inevitáveis transformações políticas, sociais, econômicas e tecnológicas demandam o desenvolvimento de novas posturas (Conto, Antunes Júnior, \& Vaccario, 2016), em especial com a Quarta Revolução Industrial. Nesse contexto, os fatores supracitados vêm moldando as formas de fazer negócio, de produzir e oferecer produtos e serviços, como também a maneira que as pessoas os adquirem e consomem (Picchi, 2019). Exemplo disso são os serviços personalizados prestados por meio de empresas que diversificam e focam na experiência do usuário com vistas à resolução de problemas do dia a dia, como o oferecimento de serviço de táxi pela Rappi (Ortega, 2019), a entrega de refeições com drones pela Uber (Freitas, 2019) e a expansão de lojas sem caixa pela Amazon (Carvalho, 2018). 
Mas não só a forma de fazer negócios tem mudado, como também a forma de gerenciar as pessoas. Em um contexto em que a inteligência artificial tem se mostrado uma ameaça ao modo de trabalhar, dentre os desafios vividos pelos líderes começa a surgir a necessidade de explorar aquilo que não pode ser feito pelas máquinas (International Labour Organization, 2019; Vasilieva, 2018). Segundo Picchi (2019), esta realidade demanda um perfil diferente de trabalhador e o desenvolvimento de habilidades que permitam a atuação no cenário corrente, o que também modifica os planejamentos de carreira desses profissionais.

De acordo com a International Labour Organization (2019), o trabalho no futuro (e desde já) deverá valorizar o bem-estar das pessoas e ampliar as suas oportunidades, investindo no desenvolvimento das capacidades humanas. Para Bruch e Ghoshal (2004, p. 12), "o que distingue os seres humanos de quase todas as outras espécies são duas coisas - imaginação e força de vontade". Para tanto, as empresas têm buscado implementar práticas que viabilizam o aumento da qualidade de vida no trabalho, eficiência e produtividade, também visando à ação criativa para alcance dos objetivos estratégicos (Ortmann \& Sydow, 2018; Picchi, 2019; Tsai, Horng, Liu, \& Hu, 2015; Zhu, Gardner, \& Chen, 2016).

Também, considerando que as pessoas dedicam boa parte do seu tempo ao trabalho e/ou a suas carreiras, em particular no Brasil (Donato, 2011), tais iniciativas caracterizam meios de gerar valor ao funcionário e contribuir para a sua felicidade no ambiente de trabalho. Aliás, Gibb e Waight (2005), Ortmann e Sydow (2018) e Picchi (2019) apontam que a criatividade humana permite a criação, gerenciamento e disseminação das tecnologias em ascensão, como também a resolução dos novos e complexos desafios. Partindo dessas reflexões, argumenta-se que estimular e desenvolver a imaginação, força de vontade e criatividade dos funcionários são movimentos necessários à sobrevivência das organizações no contexto atual e, portanto, à manutenção da competitividade.

Reforça-se que os seres humanos, por natureza, têm limitações e falham, porém, ao mesmo tempo, são os responsáveis pelas negociações inerentes à tomada de decisão e ação nas companhias (Martinelli, Nielsen, \& Martins, 2004). Dessa forma, além de possibilitar resultados superiores às empresas, tais iniciativas são favoráveis ao bem-estar das equipes. Bruch e Ghoshal (2004) destacam que os líderes devem criar nas pessoas a capacidade de sonhar e, portanto, agir de maneira intencional a partir da imaginação e da força de vontade. Enquanto isso, Hemlin, Allwood e Martin (2008) indicam a necessidade de identificar os processos que movem os funcionários à ação criativa.

Diante do exposto, questionou-se: como as organizações estão investindo em seus funcionários para se adaptar às novas realidades em constante mutação? As práticas de gestão 
de pessoas estão viabilizando a ação criativa e intencional? Para Bruch e Ghoshal (2004), Hemlin, Allwood e Martin (2008) e Moura (2019), é preciso que o ambiente propicie e inspire o fortalecimento dessas habilidades e comportamentos, especialmente a área de recursos humanos (Egan, 2005; Gibb \& Waight, 2005). Sabendo disso, o objetivo deste artigo foi analisar as práticas de gestão de pessoas (GP) associadas às ações criativa e intencional. Para esta investigação, realizou-se uma análise de conteúdo dos relatórios administrativos e notas explicativas das três instituições financeiras com ações na bolsa de valores brasileira (B3) - Itaú Unibanco S.A., Banco Bradesco S.A. e Banco do Brasil S.A - possuidoras dos maiores índices de felicidade no trabalho segundo ranking da Revista Exame (Granato, 2018).

Tais organizações foram escolhidas em virtude do ambiente cada vez mais desafiador trazido pela expansão das fintechs - empresas financeiras inovadoras com fortes traços tecnológicos (Fonseca, 2018), o que indica uma necessidade de adaptação e desenvolvimento de pessoas para a manutenção da competitividade (Denning, 2018). Inclusive, no mesmo ranking utilizado (Granato, 2018), duas fintechs constam na lista, porém não foram pesquisadas por não terem ações na B3 e não divulgarem seus relatórios administrativos, o que impediria o acesso aos dados analisados. Considerando que desde 2015 os bancos tradicionais têm sofrido os impactos da atuação destas empresas na prestação de serviços bancários, em particular no que tange a investimentos, cartões e adquirentes (Fonseca, 2018), despertou-se o interesse em compreender como essas instituições estão se posicionando diante deste cenário.

\section{Referencial teórico}

Acompanhando as pressões da globalização, modificações na sociedade, crises econômicas, aumento das exigências dos clientes e avanços tecnológicos, a forma de fazer negócios e gerenciar recursos também se reajustaram. Nesse novo panorama, o modelo tradicional de gerir pessoas tem sido cada vez mais desvalorizado, ainda que muito praticado, principalmente por organizações com operações que demandam movimentos repetitivos e programados dos seus funcionários, como é o caso dos frigoríficos brasileiros (Repórter Brasil, 2015).

Isto posto, torna-se pertinente explicar o que caracteriza esse modelo tradicional. Quando passou a surgir no início do século XX uma forte preocupação com a eficiência dos processos, estabeleceu-se uma visão de que os funcionários são recursos a serem manejados a fim de maximizar os lucros e agradar os acionistas. Na medida em que as necessidades humanas passaram a ser melhor compreendidas e a organização tomou para si responsabilidades de 
integrar aos seus processos o desenvolvimento das pessoas, novas práticas, métodos e terminologias surgiram (Dutra, Dutra, \& Dutra, 2017; Marras, 2016). Como foi o caso da evolução dos termos recursos humanos para a gestão de pessoas, e da gestão de talentos para a gestão de gente - termos usados indistintamente neste artigo.

Assim, as mudanças no RH são fruto das transformações no cenário global em aspectos demográficos, sociais, políticos, econômicos, ambientais, entre outros. Diante disso, emprestando o raciocínio dos escritos na teoria da evolução darwinista, apenas os mais competitivos têm sobrevivido. E o que tem tornado uma organização competitiva? Alguns autores (Danquah \& Amankwah-Amoah, 2017; Gibb \& Waight, 2005; Moeller, Maley, Harvey, \& Dabic, 2016; Ortmann \& Sydow, 2018; Perry-Smith, 2006; Picchi, 2019) consideram que o momento atual pede criatividade que, por sua vez, se materializa em atividades e ambientes organizacionais inovadores. Na mesma linha de raciocínio, Beugelsdijk (2008), Denning (2018) e Malik, Froese e Sharma (no prelo) indicam que as práticas atuais de RH dão suporte necessário aos processos em curso.

Segundo Denning (2018), as práticas de RH criam espaço para que as pessoas contribuam para a formação da estratégia, encorajando a autonomia, ação criativa e intencional, além de facilitar a tomada de decisão instaurando uma cultura de autorresponsabilidade, o que quebra o engessamento proveniente de cadeias de comando rígidas. Essa postura permite que as empresas permaneçam competitivas em ambientes muito inconstantes, mutáveis e que demandam predição de cenários (Eriksson, 2014; Hotho \& Champion, 2011; Makkonen, Pohjola, Olkkonen, \& Koponen, 2014). Portanto, o desenvolvimento e manutenção desta competitividade se relaciona à atenção ao capital humano (Danquah \& Amankwah-Amoah, 2017; Gibb \& Waight, 2005; Kramar, 2013; Malik et al., no prelo; Ployhart \& Moliterno, 2011).

Ademais, os processos devem ser pensados desde o recrutamento e seleção, treinamento e desenvolvimento até os mecanismos de motivação, recompensa e acompanhamento visando subsidiar a criação de conhecimentos (Kianto, Sáenz, \& Aramburu, 2017; Kramar, 2013). Isso porque para desenvolver posturas mais criativas é preciso que haja uma cultura de aprendizagem que valorize a colaboração em todos os contextos (Beugelsdijk, 2008; Gibb \& Waight, 2005; Kang, Morris, \& Snell, 2007), também promovendo a ação intencional e imaginação (Bruch \& Ghoshal, 2004; Gibb \& Waight, 2005), bem como a satisfação pessoal com o dever cumprido (Gibb \& Waight, 2005; International Labour Organization, 2019).

Isso posto, gerir pessoas estrategicamente requer estimular o aprendizado e desenvolvimento, ampliar suas oportunidades, dar abertura à criatividade, valorizar a adaptabilidade em detrimento às rotinas e estabilidade, tolerar o erro e visar o bem-estar das 
equipes (Denning, 2018; Hotho \& Champion, 2011; International Labour Organization, 2019; Storey, 2005). Ainda, Ortmann e Sydow (2018) destacam a criatividade humana como elemento que permite a resolução dos novos e complexos desafios tão presentes agora e no futuro. Compreende-se aqui que agir criativamente significa gerar ideias novas e úteis (Rigolizzo \& Amabile, 2015), como também que atuar em uma equipe criativa viabiliza inovações (Amabile, Conti, Coon, Lazenby, \& Herron, 1996).

Nesse cenário, Denning (2018) sugere práticas de gestão de pessoas necessárias à manutenção da competitividade, são elas: avaliação de desempenho, coaching, desenvolvimento de equipes, mecanismos de recompensa, aprendizagem e recrutamento. $\mathrm{O}$ autor enfatiza a importância de um feedback contínuo, autonomia na tomada de decisão, geração de valor compartilhada, diversidade das equipes e o uso de aparatos tecnológicos e inteligência artificial, incluindo plataformas online de treinamento. Em complemento, Beugelsdijk (2008) ressalta as contribuições dos treinamentos, rotação de cargos, horários de trabalho flexíveis e pagamento por desempenho à capacidade organizacional de inovar.

Em abordagem semelhante, Malik et al. (no prelo) destacam o recrutamento, treinamento e desenvolvimento, gestão por competências, trabalho em equipe, compartilhamento de informações e conhecimentos, verticalização das unidades de negócio, questionamentos e mudanças estruturais como elementos que potencializam a capacidade de a organização transformar seus inputs em novos produtos, negócios, modelos e processos. Enquanto isso, Kramar (2013) afirma que a implementação das práticas de RH pode ser mais bem-sucedida com o apoio do diretor executivo, como também pela comunicação constante com os funcionários, principalmente os gerentes.

Com vistas ao fomento da ação criativa, faz-se necessário que as pessoas dominem competências para a resolução de problemas e a realização de suas atividades-fim, tenham estilos cognitivos e características pessoais que sustentem as capacidades criatividades - tais como tolerância à ambiguidade, colaboração e disseminação de ideias -, motivem-se à realização das tarefas e estejam em um ambiente social que inspire esses comportamentos, como por exemplo oportunizando treinamentos, dando suporte à tentativa e erro, entre outros (Rigolizzo \& Amabile, 2015). Dessa forma, observa-se que a criatividade envolve tanto a ação do indivíduo quanto o ambiente em que se está inserido.

Como aponta Waight (2005), as práticas de RH conectam-se com o incentivo à criatividade na medida em que a aprendizagem, motivação, definição de objetivos, liderança e desenho dos cargos permeiam o contexto organizacional e, portanto, orientam os padrões comportamentais. Ao mesmo tempo, as práticas que contribuem à manutenção da 
competitividade citadas anteriormente (Beugelsdijk, 2008; Denning, 2018) também subsidiam a ação criativa (Alencar \& Bruno-Faria, 1997; Egan, 2005; Hemlin, 2009). Sob o mesmo ângulo, Gibb e Waight (2005) indicam três estratégias promovidas pelo RH que podem estimular o desenvolvimento da criatividade nas organizações: facilitar o entendimento, ajustar para o que engaja as pessoas e encorajar relações pelo diálogo e comunicação.

Também, Gratton e Ghoshal (2002) enfatizam a importância da qualidade das conversações no ambiente de trabalho visando promover diálogos criativos, isto é, que combinem a estruturação de pensamentos analíticos com o envolvimento emocional, levando os grupos da fragmentação à unidade. Nesse contexto, as lideranças surgem como importantes contribuintes a estes processos (Bruch \& Ghoshal, 2004; Gratton \& Ghoshal, 2002; Hemlin et al., 2008; Hemlin, 2009; Kramar, 2013). Diante do exposto, percebe-se a relevância de se criar um ambiente favorável ao desenvolvimento das pessoas e, por consequência, ao florescer da criatividade (Alencar \& Bruno-Faria, 1997; Amabile et al., 1996; Hemlin, 2009; Ortmann \& Sydow, 2018; Tsai et al., 2015).

Aliás, investir nas capacidades e conhecer os meios para a ação criativa não é o bastante. Bruch e Ghoshal (2004) chamam a atenção para o fato de que a gestão se torna falha quando os funcionários não agem de maneira intencional. Em outras palavras, "ainda que as pessoas saibam o que precisa ser feito, elas simplesmente não fazem" (Bruch \& Ghoshal, 2004, p. 6). Portanto, argumenta-se que para que as organizações desempenhem bem a gestão de pessoas no contexto atual, é preciso pavimentar caminhos para a ação criativa, ao mesmo tempo em que se estimula a ação intencional.

Com efeito, entende-se que as ações intencionais são "determinadas, persistentes e implacáveis para atingir uma meta ou objetivo contra todas as possibilidades" (Bruch \& Ghoshal, 2004, p. 6-7). Para os autores, essa postura é consequência de um compromisso pessoal, força de vontade e busca por sucesso. Ao mesmo tempo, Gibb e Waight (2005) consideram que quanto mais se desenvolve o pensamento criativo, mais as pessoas, de fato, agem. Contudo, a ação intencional se diferencia por demandar muito foco e energia (Bruch \& Ghoshal, 2004). Nesse sentido, a chave para inspirar a ação criativa e intencional reside na lapidação do potencial humano, inspirados pelos líderes e demais elementos contextuais.

Ademais, um pré-requisito para a ação intencional é saber o que precisa ser feito e o porquê (Bruch \& Ghoshal, 2004). A questão é que, o que parece óbvio nem sempre é praticado. Diante disso, é necessário que a empresa comunique a todas as equipes sua estratégia, planos, objetivos, valores e propósito (Moura, 2019; Silveira, 2019). Aliás, acredita-se que por esta razão diversos autores (Alencar \& Bruno-Faria, 1997; Amabile et al., 1996; Denning, 2018; 
Gibb \& Waight, 2005; Gratton \& Ghoshal, 2002; Kramar, 2013) apresentaram a importância do feedback, do diálogo e da comunicação constante.

\section{Procedimentos metodológicos}

Diante do objetivo proposto, foram considerados os dados dos relatórios administrativos e notas explicativas das instituições financeiras brasileiras pesquisadas de acordo com o ranking (Granato, 2018) que divulgou o índice de felicidade dos funcionários no trabalho, são elas, em ordem: Itaú Unibanco S.A., Banco Bradesco S.A. e Banco do Brasil S.A. Tais instituições são, também, as maiores do país em termos de ativos totais. Para acesso aos relatórios administrativos e notas explicativas, foram realizados downloads no site da B3 (Brasil, Bolsa, Balcão), a bolsa de valores oficial do Brasil, e nos sites das próprias instituições.

$\mathrm{Na}$ Figura 1 a seguir, está disposto o percurso metodológico da pesquisa. O período de coleta dos referidos documentos se deu entre os dias 19 e 21 de outubro de 2019 e estes foram tratados ao longo do mês de novembro do mesmo ano na busca por evidências de que as práticas de gestão de pessoas subsidiam as ações criativas e intencionais. Ressalta-se também que foram utilizados os documentos mais recentes disponibilizados em 2019 relacionados aos resultados de 2018.

Figura 1. Estrutura da pesquisa 
Questões reflexivas: Como as organizações estão investindo em seus funcionários para se adaptar às novas realidades em constante mutação? As práticas de gestão de pessoas estão viabilizando a ação criativa e intencional?

Objetivo: analisar as práticas de gestão de pessoas (GP) associadas às ações criativa e intencional Contexto da pesquisa: Três instituições financeiras brasileiras com ações na B3 que possuem os maiores índices de felicidade no trabalho

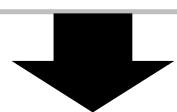

\section{Processo de Coleta dos Dados}

- Etapa 1: Obter panorama dos estudos sobre gestão de pessoas atualmente e ação criativa Realização de levantamento bibliográfico pela base da Scopus e Portal Periódicos CAPES

- Etapa 2: Acessar os documentos

Realização de download dos relatórios administrativos e notas explicativas das instituições

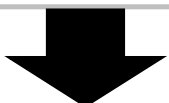

\section{Processo de Análise dos Dados}

- Etapa 1: Obter panorama dos estudos sobre gestão de pessoas atualmente e ação criativa Suporte para estabelecimento das categorias analíticas

- Etapa 2: Acessar os documentos

Codificação dos dados e agrupamento nas categorias para posterior discussão à luz das teorias, norteando-se pela técnica de análise de conteúdo (Bardin, 2011; Krippendorff, 2018; Merriam, 2009)

Optou-se pela análise de conteúdo realizando, inicialmente, a codificação e agrupamento dos dados em categorias (Bardin, 2011; Krippendorff, 2018; Merriam, 2009). Tais categorias se basearam na frequência de uso dos termos e abordagens teóricas associadas, estando dispostas na Tabela 1 a seguir junto aos seus descritores e principais autores que sustentam os conceitos propostos. Posteriormente, os elementos alocados nas categorias foram objeto de reflexão junto às teorias utilizadas a fim de se discutir os resultados. Para orientar a análise dos dados, na medida em que os relatórios eram lidos, fragmentos dos textos eram grifados com cores diferentes associadas às categorias analíticas em que se encaixavam. 
Categorias Analíticas

C1: Cenário complexo

(avanços tecnológicos, competitividade, necessidades de inovação e adaptação, modificação na forma de fazer negócios e gerir pessoas)

\section{C2: Práticas de GP}

(recrutamento e seleção, treinamento e desenvolvimento, sistema de recompensas, sistemas de aprendizagem, avaliação de desempenho, qualidade de vida no trabalho, sistemas de informações gerenciais, plano de carreiras, gestão por competências)

\section{C3: Facilitadores das ações criativas e intencionais}

(apoio das lideranças, tolerância ao erro, engajamento e bem-estar das pessoas, autonomia, diversidade, comunicação da estratégia, diálogo e feedback constante, trabalho em equipe, força de vontade, imaginação, persistência, foco e energia, capacidade de sonhar)

\section{Autores}

Conto, Antunes Júnior, \& Vaccario (2016); Fonseca (2018); International Labour Organization (2019); Lynn \& Akgün (1998); Ortmann \& Sydow (2018); Picchi (2019); Vasilieva (2018); Zhu, Gardner, \& Chen et al. (2016)

Beugelsdijk (2008); Denning (2018); Egan (2005); Gibb \& Waight (2005); Hotho \& Champion (2011); Kang, Morris, \& Snell (2007); Kianto, Sáenz, \& Aramburu (2017); Kramar (2013); Malik, Froese, \& Sharma (no prelo); McLean (2005); Tsai, Horng, Liu, \& Hu (2015); Waight (2005); Zhu et al. (2016)

Alencar \& Bruno-Faria, (1997); Amabile, Conti, Coon, Lazenby, \& Herron (1996); Bruch \& Ghoshal (2004); Denning (2018); Egan (2005); Gibb \& Waight (2005); Gratton \& Ghoshal (2002); Hemlin (2009); Hemlin et al. (2008); Hotho \& Champion (2011); International Labour Organization (2019); Kramar (2013); Ortmann \& Sydow (2018); Rigolizzo \& Amabile (2015); Storey (2005); Tsai et al. (2015); Waight (2005)

Fonte: Autores (2019)

Apoiando-se nestas categorias e informações contidas nos relatórios administrativos e notas explicativas, realizou-se a discussão dos resultados na seção abaixo.

\section{Análise e discussão dos resultados}

É unânime a menção nos relatórios administrativos e notas explicativas das instituições financeiras (Itaú Unibanco S.A., Banco Bradesco S.A. e Banco do Brasil S.A.) o cenário complexo em que estão situadas, inclusive no que diz respeito aos novos entrantes, como aponta Fonseca (2018) e o Banco do Brasil S.A. (2019), em especial as fintechs. Em virtude das transformações na sociedade, todos os bancos pesquisados apresentaram que suas estratégias estão cada vez mais voltadas à transformação digital e foco no cliente, o que sinaliza mudanças nas formas de fazer negócios (Conto et al. 2016; Picchi 2019; Vasilieva, 2018). Como consta no relatório do Itaú Unibanco Holding S.A. (2019, p. 12): “em um mundo no qual as relações estão cada vez mais digitais, o desenvolvimento de produtos e serviços deve ser feito pensando no perfil dos clientes, inclusive nos tradicionais". 
Também foram encontradas evidências no relatório do Banco Bradesco S.A. (2019, p. 14), a exemplo da modernização da marca para expressar a contemporaneidade e conectividade do momento atual, a criação da BIA (Bradesco Inteligência Artificial) para suporte aos clientes e esforços para proporcionar uma melhor experiência do usuário com ênfase "em plataformas digitais, na ampliação de produtos e serviços nos canais digitais, na criação de um banco 100\% digital [...] além da liderança mundial em inteligência artificial”. De maneira complementar, o Banco do Brasil S.A. (2019, p. 13) explica em seu relatório que "as grandes corporações financeiras têm buscado equilíbrio entre aspectos sociais, ambientais e econômicos" ao se movimentarem no cenário complexo em que atuam.

Dentro dessa perspectiva, o Banco do Brasil S.A. (2019) apresentou sua revisão estratégica para 2019 a 2023 analisando os fatores supracitados, o que resultou na identificação das chamadas megatendências, são elas: super consumidor, mundo urbano, futuro do trabalho, desing comportamental, convergência das indústrias, mudanças demográficas, recursos e sustentabilidade e tecnologias inteligentes. "A inteligência artificial, os robôs e outras tecnologias estão se tornando cada vez mais presentes no cotidiano e se inserindo em espaços que antes eram de domínio exclusivo dos humanos" (Banco do Brasil S.A., 2019, p. 15), como relatado pela International Labour Organization (2019) e Vasilieva (2018).

Considerando as previsões de novas configurações dos modelos de gestão de pessoas e empregos (Banco do Brasil S.A., 2019; International Labour Organization, 2019; Itaú Unibanco Holding S.A., 2019; Picchi, 2019), as instituições financeiras mostraram em seus documentos a atenção ao aprimoramento humano "buscando estimular a autonomia e a mobilidade das pessoas, fazendo com que se sintam cada vez mais donas do negócio e da própria carreira" (Itaú Unibanco Holding S.A., 2019, p. 22). Assim, percebe-se que o pensar estratégico das práticas de GP é essencial na busca pela manutenção competitiva (Beugelsdijk, 2018; Denning, 2018; Malik et al, no prelo). Com uma média de 98 mil funcionários, as instituições financeiras enfatizaram a relevância de cada uma dessas pessoas para o sucesso organizacional.

Visando o fortalecimento das capacidades humanas (Kianto, Sáenz, \& Aramburu, 2017; Kramar, 2013), os bancos investem maciçamente nas práticas de GP. Nesse sentido, o Banco do Brasil S.A. (2019) diagnostica as necessidades de treinamento e oferece ações educativas também por meio do UniBB, a universidade corporativa, especialmente com investimentos na formação de líderes pelos programas "Mentoria Rede Varejo", "aTUAção - Jornada do Líder Inspirador", "Liderança Feminina" e "Trilha Estratégia e Planejamento", que contribuem à soma de mais de 100 milhões de reais em capacitações. Estes programas sinalizam a formação de competências gerenciais necessárias à inspiração das equipes, conforme Bruch \& Ghoshal 
(2004); Gratton \& Ghoshal (2002); Hemlin (2009); Hemlin et al. (2008) e Kramar (2013), o que também denota a presença de facilitadores das ações criativas e intencionais.

Similarmente, o Banco Bradesco S.A. (2019) afirmou incentivar o treinamento e desenvolvimento dos funcionários por meio de uma universidade corporativa (UniBrad), programas de coaching executivo, mentoring, patrocínio a cursos de pós-graduação, programas de desenvolvimento gerencial, além de realizar a gestão por competências, avaliações de desempenho, ações voltadas à qualidade de vida no trabalho, propor um programa atrativo de benefícios, entre outros. Em linhas gerais, os bancos também buscam vincular o cenário de transformação digital à capacitação dos funcionários, realizando treinamentos em plataformas online (Denning, 2018), como também trazendo conteúdos sobre tecnologias avançadas, auxiliando no desenvolvimento competências necessárias ao cenário complexo atual, de modo a ampliar suas oportunidades (International Labour Organization, 2019)

Já no que tange a motivações extrínsecas, além de remunerações fixas, existem remunerações variáveis pautadas na meritocracia (Banco do Brasil S.A., 2019; Itaú Unibanco Holding S.A., 2019). Diante do exposto, observa-se que as práticas de GP nestas organizações são amplas e bem estruturadas. Inclusive, as instituições já foram premiadas neste âmbito como as Melhores Empresas para Trabalhar (Banco Bradesco S.A., 2019; Banco do Brasil S.A., 2019), com o Top of Mind (Banco do Brasil S.A., 2019) e apresentadas com os maiores índices de felicidade no trabalho pelo ranking da Revista Exame (Granato, 2018).

Logo, percebe-se que as práticas de GP sustentam os elementos facilitadores das ações criativas e intencionais (Alencar \& Bruno-Faria, 1997; Egan, 2005; Gibb \& Waight, 2005; Hemlin, 2009). Como exemplo, o Banco Bradesco S.A. (2019, p. 19) indicou: "além de treinar nossas equipes, também buscamos agregar novas competências, como designers, antropólogos, psicólogos sociais, cientistas de dados, history tellers", o que denota o estímulo à diversidade organizacional (Denning, 2018). Este incentivo também é adotado pelas outras instituições, inclusive com outro viés, a exemplo de programas que visam à equidade de gênero, como o "Pró-Equidade de Gênero e Raça" do Banco do Brasil, e as diretrizes de valorização do respeito às diferenças (Banco Bradesco, 2019; Banco do Brasil S.A., 2019; Itaú Unibanco Holding S.A., 2019).

Nessa busca por promover o bem-estar dos funcionários (International Labour Organization, 2019; Ortmann \& Sydow, 2018; Picchi, 2019; Tsai et al., 2015; Zhu et al., 2016), "valorizar as pessoas como elas são, suas experiências, suas características e seus modelos mentais, eliminando barreiras para que todos os colaboradores possam desenvolver seu potencial e que possamos alcançar a melhor versão de cada um de nós" norteia as práticas de 
GP do Itaú Unibanco Holding S.A. (2019, p. 52). É importante salientar que esta perspectiva de autoconhecimento e lapidação do ser humano embutida no discurso do Itaú Unibanco S.A. configura um meio de desenvolver os facilitadores foco, energia e força de vontade, indicados por Bruch e Ghoshal (2004), como também características pessoais que sustentam as capacidades criativas, conforme Rigolizzo e Amabile (2015).

De outra forma, o Banco do Brasil S.A. (2019) desenvolve ações com vistas à adoção de um estilo de vida mais saudável por parte de seus funcionários e a minimização dos problemas de saúde, como exemplo a "Trilha Bem-estar", o "Programa de Controle Médico de Saúde Ocupacional”, “Análise Ergonômica dos Postos de Trabalho”, "Exame Periódico de Saúde”, entre outros. Além de iniciativas similares, o Banco Bradesco S.A. (2019, p. 151) também possui em algumas de suas unidades de negócio a certificação OHSAS 18001:2007, "que define um conjunto de procedimentos implementados por meio de um sistema de gestão de segurança e saúde ocupacional”.

Outros facilitadores às ações criativas e intencionais importantes são os feedbacks, diálogos e comunicação constantes (Alencar \& Bruno-Faria, 1997; Amabile et al., 1996; Denning, 2018; Gibb \& Waight, 2005; Gratton \& Ghoshal, 2002; Kramar, 2013). Verificou-se que todas as instituições têm esse respaldo, contudo, o Banco do Brasil S.A. (2019) deu uma maior ênfase à comunicação organizacional, explicitando seus planos e programas voltados à disseminação de medidas estratégicas, como indicam Moura (2019) e Silveira (2019). Enquanto isso, o Banco Bradesco e o Itaú Unibanco enfatizaram os feedbacks relacionados às práticas de GP.

Como exemplo, as avaliações de desempenho: "fazem parte desse exercício feedbacks, a oferta de oportunidades de desenvolvimento adequadas às necessidades de cada colaborador e o papel do próprio colaborador de buscar continuamente melhores oportunidades" (Itaú Unibanco Holding S.A., 2019, p. 52). Ao mesmo tempo, compreendem-se os diálogos constantes embutidos em outras práticas, como o mentoring: "visa acelerar e alavancar o desenvolvimento de líderes diante dos desafios do mercado na preparação de novos líderes, por meio da transferência de conhecimento e experiência". Ambos os exemplos também denotam o aspecto do desenvolvimento do potencial humano necessário às ações criativas e intencionais (Bruch \& Ghoshal, 2004; Gibb \& Waight, 2005; International Labour Organization, 2019; Rigolizzo \& Amabile, 2015)

No que se refere ao trabalho em equipe, percebeu-se o esforço em acompanhar as demandas do cenário complexo atual (Picchi, 2019), criando "times multidisciplinares em células ágeis, com mais autonomia e colaboração" (Itaú Unibanco Holding S.A., 2019, p. 73). 
Fora do cotidiano de trabalho, essas interações também se dão no âmbito da universidade corporativa, de modo que "são feitos todos os anos encontros com as equipes, inclusive dos campi” (Banco Bradesco S.A., 2019, p. 147). De outra forma, o trabalho em equipe também pode se estender à colaboração entre empresas, inclusive fintechs (Banco Bradesco S.A., 2019; Banco do Brasil S.A., 2019). Nesse sentido, entende-se que estas iniciativas viabilizam a colaboração em diferentes contextos e contribuem para a formação de uma cultura de aprendizagem, como indicado por Beugelsdijk (2008), Gibb e Waight (2005) e Kang et al. (2007). Diante do exposto ao longo da seção, corroborou-se que as práticas e processos adotados também são úteis à criação de conhecimentos (Kianto, Sáenz, \& Aramburu, 2017; Kramar, 2013).

\section{Considerações finais}

Como principais achados deste artigo, destaca-se o compromisso das instituições financeiras (Itaú Unibanco S.A., Banco Bradesco S.A. e Banco do Brasil S.A.) com as adaptações necessárias ao cenário atual, o que é apresentado nos documentos consultados como transformação digital e centralidade no cliente. Essas adequações visam combinar as competências humanas com tecnologias de ponta, como blockchain, inteligência artificial e data Science para promover uma melhor experiência aos consumidores. Nesse sentido, conforme arcabouço teórico utilizado, as práticas de GP sustentam tais movimentações estratégicas necessárias à manutenção da competitividade, além de subsidiarem a ação criativa e intencional.

Diante disso, o presente estudo contribui aos estudos da temática de maneiras diferentes. Primeiro, por relacionar as práticas de GP aos facilitadores da criatividade e intencionalidade das ações em um cenário complexo, o que ainda é escasso no campo de estudos e demanda novas pesquisas, conforme arcabouço teórico utilizado. Segundo, evidenciando as ações das maiores instituições financeiras do país em um mercado que cada vez mais demanda agilidade, flexibilidade e fluidez, trazendo um panorama do fomento à ação criativa e intencional no segmento que também é útil ao mapeamento das iniciativas, inclusive por organizações de setores diferentes. Além disso, acredita-se que a descrição do percurso metodológico, em particular as orientações analíticas dispostas na Tabela 1, pode guiar pesquisas futuras dentro do tema. Assim, em resposta à questão de pesquisa, verificou-se que as organizações, de fato, investem no potencial humano a fim de alcançarem seus objetivos. 
Ressalta-se como limitação da pesquisa o uso de uma única fonte de dados (relatórios administrativos e notas explicativas), uma vez que se entende que o contato com o campo de pesquisa, considerando a observação do cotidiano das instituições e o diálogo com as equipes, poderia ampliar a visão acerca de como os processos são aplicados e contribuem, na prática, às ações criativas e intencionais. Ademais, algumas inquietações ocasionaram as seguintes sugestões para pesquisas futuras: qual a efetividade das práticas de $\mathrm{RH}$ aplicadas para a promoção da criatividade e intencionalidade? Isto é, como saber o que e/ou quem contribui mais e/ou melhor ao aumento das ações criativas e intencionais? Quais aspectos diferenciam, por exemplo, agências bancárias com melhores e piores índices de desempenho dos funcionários? Quais combinações de práticas de RH melhor subsidiam a criatividade e intencionalidade?

\section{Referências}

Alencar, E. M. L. S., \& Bruno-Faria, M. de (1997). Characteristics of an organizational environment which stimulate and inhibit creativity. Journal of Creative Behavior, 31(4), 271-281. https://doi.org/10.1002/j.2162-6057.1997.tb00799.x

Amabile, T. M., Conti, R., Coon, H., Lazenby, J., \& Herron, M. (1996). Assessing the work environment for creativity. Academy of Management Journal, 39(5), 1154-1185. https://doi.org/10.5465/256995

Banco Bradesco S.A. (2019). Relatório integrado 2018 - Versão Complementar. Osasco: Autor. Recuperado de https://www.bradescori.com.br/siteBradescoRI/uploads/file/Vers\%C3\%A3o\%20final(6). pdf

Banco do Brasil S.A. (2019). Relatório anual 2018. Brasília: Autor. Recuperado de https://s3.amazonaws.com/mz-filemanager/5760dff3-15e1-4962-9e81322a0b3d0bbd/4ae84766-e2fd-4317-80ed0eb399a80b02_BB\%20Relato\%CC\%81rio\%20Anual\%202018.pdf

Bardin, L. (2011). Análise de conteúdo. São Paulo: Edições 70.

Bruch, H., \& Ghoshal, S. (2004). Management is the art of doing and getting done. Business Strategy Review, 15(3), 4-13. https://doi.org/10.1111/j.1467-8616.2010.00666.x 
Carvalho, I. (2018). Amazon pretende abrir 3 mil lojas sem caixas até 2021. StartSe. Recuperado de https://www.startse.com/noticia/corporate/55250/amazon-pretende-abrir3-mil-lojas-sem-caixas-ate-2021

Conto, S. M., Antunes Júnior, J. A. V., \& Vaccaro, G. L. R. (2016). A inovação como fator de vantagem competitiva: estudo de uma cooperativa produtora de suco e vinho orgânicos. Gestão \& Produção, 23(2), 397-407. http://dx.doi.org/10.1590/0104-530x1677-14

Danquah, M., \& Amankwah-Amoah, J. (2017). Assessing the relationships between human capital, innovation and technology adoption: Evidence from sub-Saharan Africa. Technological Forecasting \& Social Change, 122, 24-33. https://doi.org/10.1016/j.techfore.2017.04.021

Denning, S. (2018). The emergence of Agile people management. Strategy \& Leadership, 46(4), 3-10. https://doi.org/10.1108/SL-04-2018-0042

Donato, V. (2011). Quase metade dos brasileiros trabalha até onze horas por dia. Jornal Hoje. Recuperado de http://g1.globo.com/jornal-hoje/noticia/2011/12/quase-metade-dosbrasileiros-trabalha-ate-onze-horas-por-dia.html

Dutra, J. S., Dutra, T. A., \& Dutra, G. A. (2017). Gestão de Pessoas: realidade atual e desafios futuros. São Paulo: Atlas.

Egan, T. M. (2005). Factors Influencing Individual Creativity in the Workplace: An Examination of Quantitative Empirical Research. Advances in Developing Human Resources, 7(2), 160-181. https://doi.org/10.1177/1523422305274527

Eriksson, T. (2014). Processes, antecedents and outcomes of dynamic capabilities. Scandinavian Journal of Management, 30(4), 65-82. https://doi.org/10.1016/j.scaman.2013.05.001

Fonseca, M. (2018). Pesquisa mostra o abismo entre bancos e fintechs - e seus clientes. Revista Exame. Recuperado de https://exame.abril.com.br/pme/pesquisa-mostra-o-abismo-entrebancos-e-fintechs-e-seus-clientes/

Freitas, T. (2019). Esse é o drone que fará o delivery de refeições no Uber Eats. StartSe. Recuperado de https://www.startse.com/noticia/nova-economia/70296/uber-eats-drone 
Gibb, S., \& Waight, C. L. (2005). Connecting HRD and Creativity: From Fragmentary Insights to Strategic Significance. Advances in Developing Human Resources, 7(2), 271-286. https://doi.org/10.1177/1523422305274530

Granato, L. (2018). Conheça as 150 Melhores Empresas para Trabalhar de 2018. Revista Exame. Recuperado de https://exame.abril.com.br/carreira/conheca-as-150-melhoresempresas-para-trabalhar-de-2018/

Gratton, L., \& Ghoshal, S. (2002). Improving the quality of conversations. Organizational Dynamics, 31(3), 209-223. https://doi.org/10.1016/S0090-2616(02)00110-9

Hemlin, S. (2009). Creative Knowledge Environments: An Interview Study with Group Members and Group Leaders of University and Industry R\&D Groups in Biotechnology. Creative Knowledge Environments, 18(4), 278-285. https://doi.org/10.1111/j.14678691.2009.00533.x

Hemlin, S., Alwood, C. M., \& Martin, B. R. (2008). Creative Knowledge Environments. Creativity Research Journal, 20(2), 196-210. https://doi.org/10.1007/978-1-4614-38588_200001

Hotho, S., \& Champion, K. (2011). Small businesses in the new creative industries: innovation as a people management challenge. Management Decision, 49(1), 29-54. https://doi.org/10.1108/00251741111094428

International Labour Organization. (2019). Work for a brighter future. Geneva: Autor. Recuperado de https://drive.google.com/file/d/1SKkO_KeA40fX29ohyMHDs2EeWdH_B_TA/view

Itaú Unibanco Holding S.A. (2019). Relatório integrado 2018. São Paulo: Autor. Recuperado de https://www.itau.com.br/relacoes-com-investidores/relatorio-anual/2018/pdf/pt/relatointegrado-2018.pdf

Kang, S. C., Morris, S. S., \& Snell, S. A. (2007). Relational archetypes, organizational learning, and value creation: Extending the human resource architecture. Academy of Management Review, 32(1), 236-256. https://doi.org/10.5465/amr.2007.23464060 
Kianto, A., Sáenz, J., \& Aramburu, N. (2017). Knowledge-based human resource management practices, intellectual capital and innovation. Journal of Business Research, 81, 11-20. https://doi.org/10.1016/j.jbusres.2017.07.018

Kramar, R. (2013). Beyond strategic human resource management: is sustainable human resource management the next approach? The International Journal of Human Resource Management, 25(8), 1069-1089. https://doi.org/10.1080/09585192.2013.816863

Krippendorff, K. (2018). Content analysis: an introduction to its methodology (4a ed.). Los Angeles: SAGE.

Lynn, G. S., \& Akgün, A. E. (1998). Innovation strategies under uncertainty: a contingency approach for new product development. Engineering Management Journal, 10(3), 11-18. https://doi.org/10.1080/10429247.1998.11414991

Makkonen, H., Pohjola, M., Olkkonen, R., \& Koponen, A. (2014). Dynamic capabilities and firm performance in a financial crisis. Journal of Business Research, 67(1), 2707-2719. https://doi.org/10.1016/j.jbusres.2013.03.020

Malik, A., Froese, F. J., \& Sharma, P. (no prelo). Role of HRM in knowledge integration: Towards a conceptual framework. Journal of Business Research, 2019. https://doi.org/10.1016/j.jbusres.2019.01.029

Marras, J. P. (2016). Administração de recursos humanos: do operacional ao estratégico. São Paulo: Saraiva.

Martinelli, D. P., Nielsen, F. A. G., \& Martins, T. M. (2004). Negociação: conceitos e aplicações práticas. São Paulo: Atlas.

Merriam, S. B. (2009). Qualitative research: a guide to design and implementation. San Francisco: Jossey-Bass.

Moeller, M., Maley, J., Havey, M., \& Dabic, M. (2016). People management and innovation in emerging market multinationals: a competency-based framework. Journal of Management Development, 35(4), 530-548. https://doi.org/10.1108/JMD-04-2015-0053

Moura, E. (2019). Comprometimento do pessoal: pré-requisito ou resultado? Revista ADNormas. 
https://revistaadnormas.com.br/2019/09/10/comprometimento-do-pessoal-pre-requisitoou-resultado-2/

Ortega, J. (2019). Rappi oferece serviço de táxi em mais um passo para se tornar super app. StartSe. Recuperado de https://www.startse.com/noticia/startups/71532/rappi-taxi

Ortmann, G., \& Sydow, J. (2018). Creativity in/of Organizations for Managing Things to Come - Lessons to Be Learnt from Philosophy. In H. Kramer \& M. Wenzel (Eds.), Strategic entrepreneurship: Creating a new mindset (Cap. 4, pp. 67-88). London: Palgrave Macmillan.

Perry-Smith, J. E. (2006). Social yet creative: the role of social relationships in facilitating individual creativity. Academy of Management Journal, 49(1), 85-101. https://doi.org/10.5465/amj.2006.20785503

Picchi, F. A. (2019). Como a transformação digital pode influenciar no plano de carreira. Revista ADNormas. Recuperado de https://revistaadnormas.com.br/2019/09/17/como-atransformacao-digital-pode-influenciar-no-plano-de-carreira/

Ployhart, R. E., \& Moliterno, T. P. (2011). Emergence of the human capital resource: a multilevel model. Academy of Management Review, 36(1), 127-150. https://doi.org/10.5465/amr.2009.0318

Repórter Brasil. (2015, Janeiro 21). Carne, Osso. [Arquivo de vídeo]. Recuperado de https://vimeo.com/117457305

Rigolizzo, M., \& Amabile, T. (2015). Entrepreneurial Creativity: The Role of Learning Processes and Work Environment Supports. In C. E. Shalley, M. A. Hitt, \& J. Zhou (Eds.), The Oxford Handbook of Creativity, Innovation and Entrepreneurship (pp. 61-78). New York: Oxford University Press.

Silveira, C. B. (2019). O que é o hoshin kanri. Revista ADNormas. Recuperado de https://revistaadnormas.com.br/2019/09/10/o-que-e-o-hoshin-kanri/

Storey, J. (2005). Human resource policies for knowledge work. In S. Little, \& T. Ray (Eds.), Managing Knowledge (pp. 199-220). London: SAGE.

Tsai, C. Y., Horng, J. S., Liu, C. H., \& Hu, D. C. (2015). Work environment and atmosphere: The role of organizational support in the creativity performance of tourism and hospitality Revista Gestão e Secretariado (GeSec), São Paulo, SP, 12(2), maio/ago., 2021, 253-272. 
organizations. International Journal of Hospitality Management, 46, 26-35. https://doi.org/10.1016/j.ijhm.2015.01.009

Vasilieva, E. V. (2018). Developing the Creative Abilities and Competencies of Future Digital Professionals. Nauchno-Tekhnicheskaya Informatsiya, 2(10), 1-10. https://doi.org/10.3103/S0005105518050060

Waight, C. L. (2005). Exploring Connections Between Human Resource Development and Creativity. Advances in Developing Human Resources, 7(2), 151-159. https://doi.org/10.1177/1523422305274524

Zhu, Y. Q., Gardner, D. G., \& Chen, H. G. (2018). Relationships between work team climate, individual motivation, and creativity. Journal of Management, 44(5), 2094-2115. https://doi.org/10.1177/0149206316638161

Submetido em: 08.09 .2020

Aceito em: $\quad 11.11 .2020$ 